\title{
Development and Evaluation of a Once-Daily Controlled Porosity Osmotic Pump of Tapentadol Hydrochloride
}

\author{
Hetal P. Thakkar, ${ }^{1,2}$ Nirav Pancholi, ${ }^{1}$ and Chintankumar V. Patel ${ }^{1}$
}

Received 22 August 2015; accepted 1 December 2015; published online 17 December 2015

\begin{abstract}
The present study aimed to prepare, optimize, and evaluate Tapentadol hydrochloride controlled porosity osmotic pump (CPOP) and to achieve the drug release at nearly zero-order. The CPOP was prepared by the coating of polymers (Eudragit RSPO and RLPO) on a directly compressed core tablet. A Box-behnken experimental design was applied to optimize the parameters for CPOP. The optimized batch was characterized for in vitro drug release study, effect of $\mathrm{pH}$, osmolarity and agitation intensity, and surface morphology and stability study. In vivo pharmacokinetic studies were performed on New Zealand white rabbits for CPOP and marketed tablet. All the batches showed a drug release ranging from 29.87 to $56.92 \%$ after $12 \mathrm{~h}$; and from 59.64 to $99.96 \%$ after $24 \mathrm{~h}$. There was no change in the drug release pattern at different $\mathrm{pH}$ and agitation intensities. The drug release was found to decrease with increasing osmolarity of dissolution media.An in vivo study showed a higher mean residence time, area under the curve, and biological half-life $\left(T_{1 / 2}\right)$ than the marketed tablet with low rate of elimination $(\mathrm{Ke})$ and a 2.35-fold increase in relative bioavailability. The result showed that the amounts of sodium chloride and PEG 400 were contributing positively while the number of coats was negatively affecting the drug release. The drug release was found to be independent of physiological conditions. The stability testing showed that the prepared CPOP was stable for 3 months at accelerated conditions. The prepared CPOP was found to deliver Tapentadol hydrochloride at zero-order for up to $24 \mathrm{~h}$.
\end{abstract}

KEY WORDS: controlled porosity osmotic pump (CPOP); osmogen; pore former; tapentadol hydrochloride; zero-order release.

\section{INTRODUCTION}

Chronic pain is defined by the "International Association for study of pain" as pain that persists beyond normal tissue healing time. It occurs in the context of many diseases and conditions, including cancer, back pain, osteoarthritis, trauma, fibromyalgia, diabetic neuropathy, post-operative pain, and migraine-related headache. A recent market research report indicates that more than 1.5 billion people worldwide suffer from chronic pain and that approximately $3-4.5 \%$ of the global population suffers from neuropathic pain (1).

Opioid analgesics such as Morphine sulfate, Oxycodone, Oxymorphone, Hydromorphone, Tramadol, and Tapentadol are increasingly prescribed for the treatment of painful chronic conditions (2). Despite their established place in pain management, traditional $\mu$-opioid receptor agonists are prescribed only for extreme pain as they are associated with gastrointestinal (GI) and other dose-limiting adverse events. These factors can compromise the adequacy and quality of pain management and lead to treatment discontinuation (3).

\footnotetext{
${ }^{1}$ TIFAC CORE in NDDS, Pharmacy Department, Faculty of Technology \& Engineering, The M.S. University of Baroda, Kalabhavan, Vadodara, 390 001, India.

${ }^{2}$ To whom correspondence should be addressed. (e-mail: hetal_thakkar11@yahoo.com)
}

Tapentadol hydrochloride (TAP) is the newer drug of the centrally acting analgesic class approved by USFDA in 2008, after more than 25 years from the last approved opioid analgesic Tramadol. Its potency is between the highly potent morphine and the comparatively less-potent tramadol. It has two complementary mechanisms of action within a single molecule, binding weakly to the mu-opioid receptor site and inhibiting the reuptake of norepinephrine. Its unique dual mechanism of action makes it an agent with automatic multimodal benefit (4). Presently, it is available in the form of immediate release as well as extended release tablets. It is also available in a solution dosage form for pediatric use. The immediate release tablets, Nucynta ${ }^{\circledR}$ IR Tablet; Janseen Pharmaceutica $(50,75,100 \mathrm{mg})$ are administered 3-4 times a day while the extended release tablets, Nucynta ${ }^{\circledR}$ ER Tablet; Janseen Pharmaceutica $(100-250$ mg) need to be administered twice daily (5).

The frequency of administration is high because of rapid elimination from the body as the clearance of TAP is 1530 $\pm 177 \mathrm{ml} / \mathrm{min}$, oral bioavailabilty is $32 \%$ and it is having a short half-life of $4 \mathrm{~h}(5,6)$. Frequent administration of high dose of TAP in a day increases side effects like gastric disturbance, hallucination, nausea, and vomiting. The multiple dosing leads to drug accumulation in the body resulting in severe side effects and poor patient compliance.

Conventional drug delivery systems have little control over the drug release and so effective concentration at the 
target site cannot be achieved and this kind of dosing pattern may result in unpredictable plasma concentrations. Oral controlled drug delivery dosage forms provide desired drug release pattern for longer periods of time and so the rate and extent of drug absorption from oral controlled drug delivery formulations can be predicated. Various approaches used for achieving controlled release of the drug includes, use of dissolution-controlled release systems, diffusion-controlled release systems, dissolution and diffusion-controlled release systems, ion exchange resins drug complexes, slow dissolving salts and complexes, $\mathrm{pH}$ dependent formulations, and Hydrodynamic controlled systems etc. Drug release from these formulations may be affected by $\mathrm{pH}$, GI motility, and presence of food in the GI tract. However, drug release from osmotic drug delivery system is not affected by physiological factors. Osmotically controlled systems utilize osmotic pressure for controlled delivery of the drug. Amongst the controlled release devices, osmotic systems hold a stable place because of its reliability to deliver the API at predetermined zero-order rate for prolonged period of time making them standard dosage forms for the constant delivery of contents (7).

In the present study, controlled porosity osmotic pump (CPOP) was selected amongst all osmotic delivery systems considering its advantages over other systems. CPOP works as an osmotic tablet covered with semipermeable membrane (SPM) created using uniform coating of mixture of water insoluble polymers and water-soluble pore forming agents (e.g. polyethylene glycol (PEG), urea, sorbitol etc.), wherein the delivery orifices/pores are formed in situ through leaching of pore formers. Thus, the CPOP system does not require any drilling mechanism to create pores. The amount of pore former present in the SPM controls its porosity, while the water permeability of the SPM can be controlled using an optimum ratio of high and low water permeability polymers. Release rate from CPOP depends on various factors like coating thickness, solubility of drug in tablet core, amount of leachable pore forming agent(s) and the osmotic pressure difference across the semi permeable membrane (8).

\section{MATERIALS AND METHODS}

\section{Materials}

Tapentadol hydrochloride was gifted by Ami Life Sciences Pvt. Ltd; Vadodara, India. Eudragit RLPO and Eudragit RSPO were obtained as a gift sample from Degussa India Pvt. Ltd. Mumbai, India. Polyethylene glycol 400 (PEG 400) and acetone were purchased from Spectrochem, Mumbai, India. Sodium chloride (NaCl), Polyvinyl Pyrrolidone K-30 (PVP-K30), Magnesium stearate, Aerosil 200, Microcrystalline Cellulose (MCC) were purchased from S.D. Fine Chemicals, Mumbai, India.

\section{Drug-Excipients Compatibility Study}

The drug excipient compatibility was ensured using Differential Scanning Calorimetry (DSC). 2-3 mg of sample was taken and sealed in an aluminum pan by applying external pressure. This aluminum pan was heated from 25 to $300^{\circ} \mathrm{C}$ at a scanning rate of $10^{\circ} \mathrm{C} / \mathrm{min}$ under nitrogen flow rate of $40 \mathrm{ml} /$ min to create inert environment using Shimadzu thermal analyzer (Shimadzu, DSC-60, Japan) $(9,10)$.

\section{Preparation of CPOP}

As shown in Table I, TAP and all the excipients of core tablet were accurately weighed and transferred to mortar. Mixture was triturated well for size reduction. Powder blend was passed through a \#60-mesh screen and uniformly mixed by geometrical dilution method in a polybag for $10 \mathrm{~min}$. Previously weighed magnesium stearate and Aerosil were added in the blend and again mixed for $2 \mathrm{~min}$. The pre-compression studies were performed to assure free flowing nature of the powder mixture (11). The resulting powder mixture was directly compressed using a 9-mm concave punch on a rotary tablet press (General Machinery Company, Mumbai). Prepared core tablets were evaluated for hardness, friability, thickness, and weight variation tests. Hardness of the tablets was measured using a Pfizer hardness tester (Secor India Scientific Engg. Corporation, Mumbai). Friability of the tablets was measured using a Roche friabilator (VEEGO Instruments, Mumbai). The core tablets were then film-coated to form a semipermeable membrane of 20\% $w / v$ Eudragit RSPO: Eudragit RLPO (3:1) in acetone having different quantities of PEG 400 ( $\% w / w$ of total coating polymers) as mentioned in Table I; using a spray pan coating machine (MAGUMPS, Mumbai). Coating pan of 8 in diameter was used at $30-\mathrm{rpm}$ speed and $1-3 \mathrm{ml} / \mathrm{min}$ of spraying rate. Coating was done until the desired weight gain of the core tablets was achieved. Coated tablets were dried at $40^{\circ} \mathrm{C}$ for $24 \mathrm{~h}$ in a hot air oven and evaluated for various parameters.

\section{Optimization of CPOP by Box-Behnken Design}

Box-Behnken design provides an easy and accurate way to statistically analyze three factors at three levels. This provides the class of rotatable or nearly rotatable second-order designs based on three-level incomplete factorial designs. The three-factor BoxBehnken design requires only 12 runs plus the replicates at the center point (here, five center points) (12). A three-factor, threelevel Box-Behnken design was utilized for optimization of the CPOP system. Amount of $\mathrm{NaCl}$ (\%) (osmogen), amount of PEG $400(\%)$ (pore former), and number of coats (5\% weight gain $=1$ number of coat) were selected as three independent variables $A, B$, and $C$, respectively, as these factors were found to be majorly affecting the drug release profile during preliminary trial batches. Three levels (high (+1), medium (0), and low ( -1$)$ ) of each independent variable were chosen in accordance with the preliminary trials. The actual values of the three independent variables were transformed into coded values and were used in the experimental design (Table II).

Design Expert software 7.0.0 generated 17 randomized experimental runs (Table I) for selected independent variables, including five replicates at the center points. All other formulation and processing variables were kept constant throughout the study. Cumulative amount of drug release at $12 \mathrm{~h}(\mathrm{R} 1)$ and at $24 \mathrm{~h}$ (R2) were taken as response variables.

\section{Statistical Analysis}

\section{Response Coefficient Significance Study}

Polynomial models including interaction and quadratic terms were generated for two response variables using multiple linear regression analysis (MLRA) approach. Using a 5\% level of significance, if the $P$ value was less than 0.05 ; the model and the model 
Table I. Composition of Batches ${ }^{\mathrm{a}}$ and Experimental Values for R1 and R2

\begin{tabular}{|c|c|c|c|c|c|}
\hline Batch code & $\begin{array}{l}\text { Sodium chloride } \\
\quad(\% w / w)\end{array}$ & $\begin{array}{l}\text { PEG } 400 \\
\quad(\% w / w)\end{array}$ & $\begin{array}{l}\text { Number } \\
\text { of coats }\end{array}$ & $\begin{array}{l}\text { Response R1-\% CDR } \\
\quad \text { at } 12 \mathrm{~h}(n=3)\end{array}$ & $\begin{array}{l}\text { Response R2-\% } \\
\text { CDR at } 24 \mathrm{~h}(n=3)\end{array}$ \\
\hline $\mathrm{F} 1$ & 3 & 15 & 2 & $56.92 \pm 3.02$ & $99.84 \pm 1.02$ \\
\hline $\mathrm{F} 2$ & 1 & 5 & 2 & $29.87 \pm 1.98$ & $59.64 \pm 1.92$ \\
\hline F3 & 2 & 10 & 2 & $46.73 \pm 1,23$ & $97.83 \pm 1.22$ \\
\hline F4 & 1 & 10 & 3 & $39.28 \pm 1.65$ & $77.38 \pm 3.10$ \\
\hline F5 & 2 & 5 & 3 & $31.87 \pm 1.10$ & $67.91 \pm 1.11$ \\
\hline F6 & 2 & 15 & 1 & $55.63 \pm 1.09$ & $99.96 \pm 1.17$ \\
\hline F7 & 1 & 10 & 1 & $44.96 \pm 2.03$ & $88.82 \pm 1.07$ \\
\hline F8 & 2 & 15 & 3 & $41.34 \pm 2.91$ & $82.68 \pm 1.22$ \\
\hline F9 & 2 & 10 & 2 & $49.13 \pm 1.64$ & $98.73 \pm 1.21$ \\
\hline F10 & 2 & 10 & 2 & $48.78 \pm 1.32$ & $97.83 \pm 1.75$ \\
\hline F11 & 2 & 10 & 2 & $49.73 \pm 1.11$ & $99.89 \pm 1.43$ \\
\hline F12 & 1 & 15 & 2 & $42.71 \pm 2.12$ & $74.86 \pm 1.88$ \\
\hline F13 & 2 & 5 & 1 & $39.29 \pm 3.18$ & $76.14 \pm 0.93$ \\
\hline F14 & 2 & 10 & 2 & $46.27 \pm 1.34$ & $97.80 \pm 1.27$ \\
\hline F15 & 3 & 10 & 1 & $54.63 \pm 1.43$ & $99.70 \pm 0.91$ \\
\hline F16 & 3 & 10 & 3 & $46.21 \pm 1.22$ & $91.40 \pm 2.23$ \\
\hline F17 & 3 & 5 & 2 & $38.65 \pm 1.71$ & $74.66 \pm 2.98$ \\
\hline
\end{tabular}

${ }^{a}$ In the core tablet, TAP, polyvinyl pyrrolidone (K-30), magnesium stearate, and Aerosil were fixed to 200, 6.25, 3.0, and 0.83 mg respectively. Microcrystalline cellulose (MCC) was taken quantity sufficient to fixed total weight of core tablet $250 \mathrm{mg}$

terms were considered significant. The general form of the MLRA model is represented as the following equation.

$$
\begin{aligned}
R= & b_{0}+b_{1} A+b_{2} B+b_{3} C+b_{4} A B+b_{5} A C+b_{6} B C \\
& +b_{7} A^{2}+b_{8} B^{2}+b_{9} C^{2}
\end{aligned}
$$

Where, $b_{0}$ is the intercept representing the arithmetic mean of all quantitative outcomes of 17 runs; $b_{1}-b_{9}$ are the coefficients computed from the observed experimental response values of $R ; A, B$, and $C$ are the coded values of the independent variables; $A B, A C$, and $B C$ are interaction terms and $A^{2}, B^{2}$, and $C^{2}$ are quadratic terms (12-14).

\section{Independent Factors Interaction Study}

The effect of interaction between the factors on \% CDR $12 \mathrm{~h}$ and \% CDR $24 \mathrm{~h}$ was studied graphically using the interaction profiles generated by the Design Expert software 7.0.0. The interaction study was performed to check the effect of two factors simultaneously when any one factor was fixed at constant level.

Table II. List of Variables in Box-Behnken Design

\begin{tabular}{llll}
\hline Independent variables & \multicolumn{2}{l}{ Levels used actual (coded) } \\
\cline { 2 - 4 } & Low $(-1)$ & Medium (0) & High $(+1)$ \\
\hline A $(\% w / w$ NaCl) & 1 & 2 & 3 \\
B $(\% w / w$ PEG 400$)$ & 5 & 10 & 15 \\
C (number of coats) & 1 & 2 & 3 \\
Dependent variables & Constraints & \\
$\%$ CDR $(12 \mathrm{~h})$ & $45 \% \geq \mathrm{R} 1 \leq 50 \%$ & \\
$\%$ CDR $(24 \mathrm{~h})$ & $95 \% \geq \mathrm{R} 2 \leq 100 \%$ & \\
\hline
\end{tabular}

\section{Optimization Using Desirability Plot}

A desirability plot gives optimum value of selected variables so as to obtain desired responses. Desirability plot was generated using Minitab®16 Statistical Software State College, PA: Minitab, Inc; USA. The upper and lower desired values of response were fed into the software and the optimum value for each variable was obtained (15).

\section{Validation of Polynomial Equations Generated by Model}

To evaluate the equation generated by multiple linear regression analysis, two check point batches $\mathrm{C} 1$ and $\mathrm{C} 2$ were prepared in duplicate. The values of all possible combinations of three independent variables $A, B$, and $C$ were selected randomly (Table III). The results of the check point batches were compared with the values of R1 and R2 obtained from the equation generated.

\section{Selection of Optimized Formulation}

Optimized formulation was selected based on the desirability value of the response parameter \% CDR12 $\mathrm{h}$ (R1) and \% CDR $24 \mathrm{~h}$ (R2) generated by the Minitab®16 software, within the target values of the independent variables.

\section{Characterization of CPOP}

\section{Core Tablet Evaluation}

The core tablets were evaluated for hardness, friability, thickness and weight variation. The hardness and friability of the tablets were determined by Pfizer hardness tester and Roche friabilator, respectively. Uniformity of tablet weight 
Table III. Resultant Summary for Random Check Point for Validation of Statistical Model

\begin{tabular}{|c|c|c|c|c|c|c|c|c|c|c|c|c|}
\hline \multirow[t]{2}{*}{ Batch codes } & \multicolumn{3}{|c|}{ Coded values } & \multicolumn{3}{|c|}{ Actual values } & \multicolumn{3}{|c|}{ Response R1 } & \multicolumn{3}{|c|}{ Response R2 } \\
\hline & A & $\mathrm{B}$ & $\mathrm{C}$ & A & $\mathrm{B}$ & $\mathrm{C}$ & $\mathrm{OV}^{\mathrm{a}}$ & $\mathrm{PV}^{\mathrm{b}}$ & $\mathrm{RV}^{\mathrm{c}}$ & $\mathrm{OV}^{\mathrm{a}}$ & $\mathrm{PV}^{\mathrm{b}}$ & $\mathrm{RV}^{\mathrm{c}}$ \\
\hline $\mathrm{C} 1$ & -0.5 & 0.5 & -1.0 & $1.5 \%$ & $12.5 \%$ & 1.0 & 52.81 & 51.43 & -1.38 & 96.11 & 97.34 & 1.23 \\
\hline $\mathrm{C} 2$ & 1.25 & 2.0 & 4.0 & $3.25 \%$ & $20 \%$ & 4.0 & 38.73 & 36.58 & -2.15 & 74.63 & 76.39 & 1.76 \\
\hline
\end{tabular}

${ }^{a}$ Observed value

${ }^{b}$ Predicted value

${ }^{c}$ Residual value

and thickness of the tablet were determined to confirm consistency in tablet preparation. Tablets were weighed individually to check weight variation. Limit for weight variation was set to $\pm 7.5 \%$. The thickness of the tablets was measured by digital vernier caliper and expressed in $\mathrm{mm}$.

\section{In Vitro Drug Release Study}

In vitro drug release of the formulations was carried out by using USP Type-II (Paddle) apparatus (LABINDIA DS 8000). The dissolution medium was $900 \mathrm{ml}$ of $0.1 \mathrm{~N}$ Hydrochloric acid $(\mathrm{HCl})$ for initial $2 \mathrm{~h}$ followed by phosphate buffer $\mathrm{pH} 6.8$ for remaining $22 \mathrm{~h}$. The stirring rate was $50 \mathrm{rpm}$ and dissolution media was maintained at $37 \pm 1^{\circ} \mathrm{C}$. $5 \mathrm{ml}$ of dissolution medium was withdrawn and replaced with same volume of fresh medium at 2, 4, 6, 8, 10,12 , and 24 h respectively $(16,17)$. Samples were immediately analyzed using UV spectroscopic method at $272 \mathrm{~nm}$. Drug release data of the optimized formulation were fitted to various mathematical models (Zero-order, First-order, Higuchi, Korsmeyer-Peppas, and Hixson-Crowell) to check the kinetics of drug release. Best goodness-of-fit tests $\left(r^{2}\right)$ were taken as criteria for selecting the most appropriate model (18).

\section{Investigation of Drug Release Mechanism}

There are three mechanisms that contribute to the release of active material from controlled porosity osmotic pump i.e., drug release driven by the mechanism of osmotic pressure, size and number of pores formed in the membrane and water uptake of the membrane. To demonstrate the role of osmotic pressure for drug release, the optimized formulation of controlled porosity osmotic pump was subjected to in vitro drug release study in different concentrations of $\mathrm{NaCl}$ ( 1 and $2 \mathrm{~mol} / \mathrm{l}$ ) used as dissolution medium.

\section{Effect of $p H$}

The optimized CPOP of TAP was subjected to an in vitro drug release study using three different dissolution media i.e., Hydrochloric acid buffer $\mathrm{pH}$ 1.2, phosphate buffer $\mathrm{pH} 4.5$ and $\mathrm{pH} 6.8$ using USP-II (paddle) type dissolution apparatus at $50 \mathrm{rpm}$. Drug release profiles of optimized formulation in three different dissolution media were compared using difference factor (f1) and similarity factor (f2) $(19,20)$.

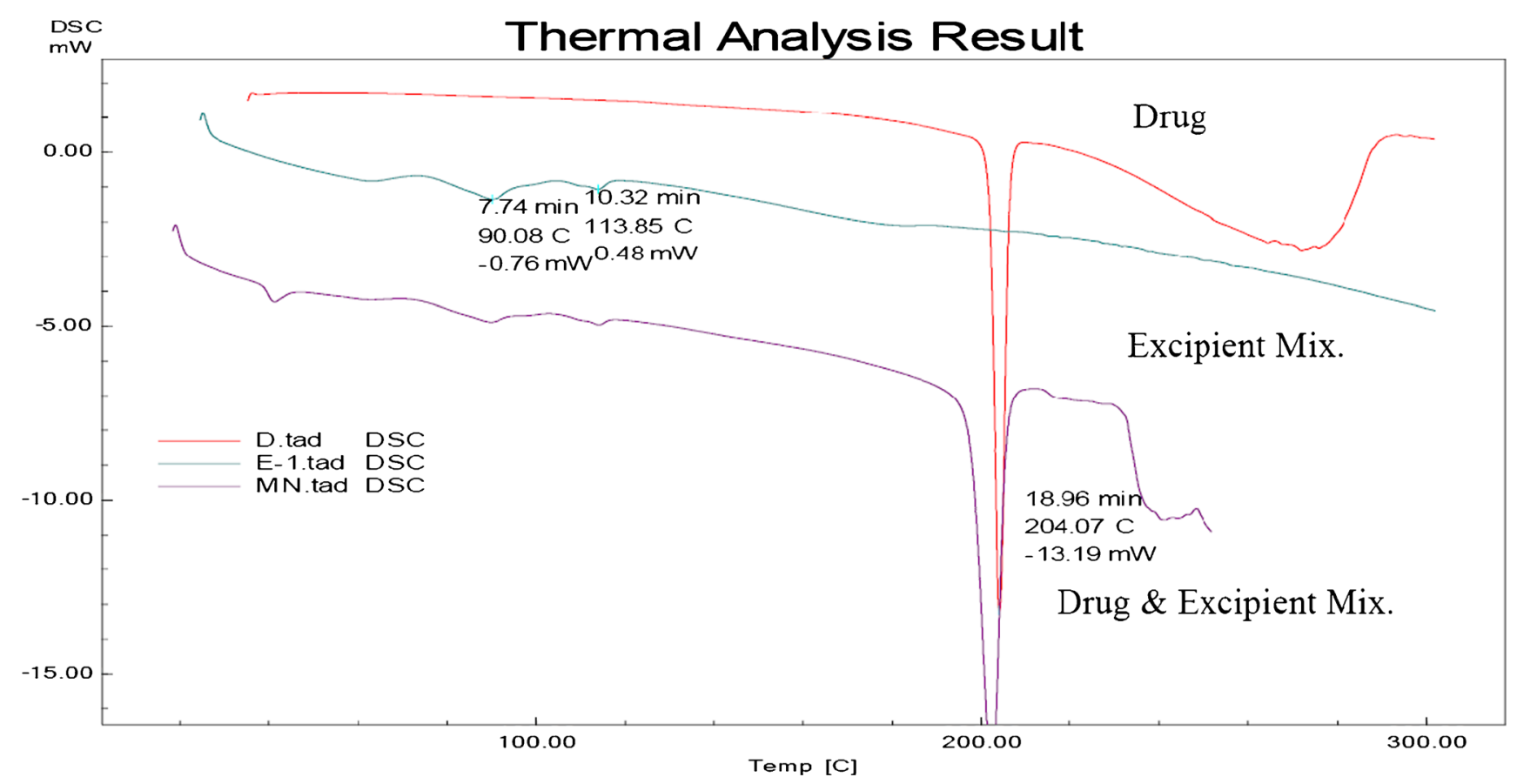

Fig. 1. DSC thermogram of TAP and its solid admixture with excipients 


\section{a DRUG RELEASE PROFILE}

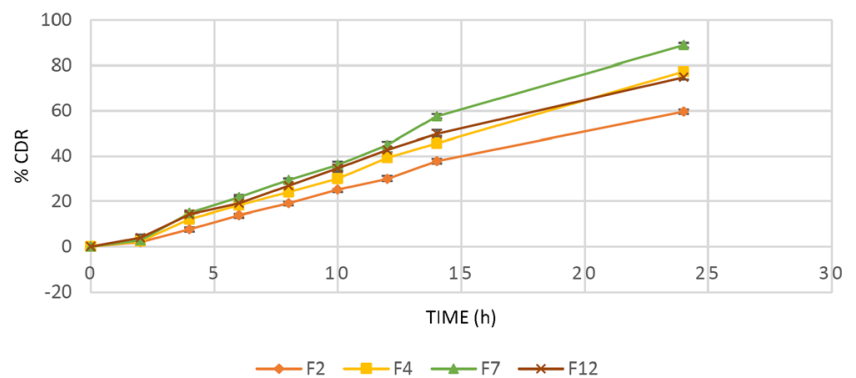

C DRUG RELEASE PROFILE

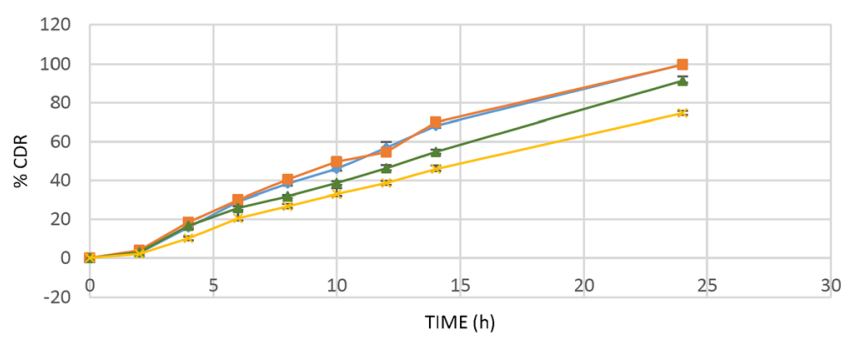

$\longrightarrow F 1 \rightarrow F 15 \longrightarrow F 16 \longrightarrow F 17$

\section{b DRUG RELEASE PROFILE}

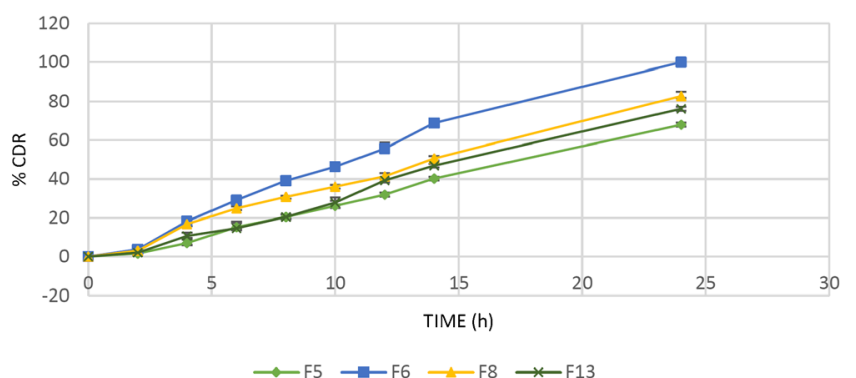

d DRUG RELEASE PROFILE

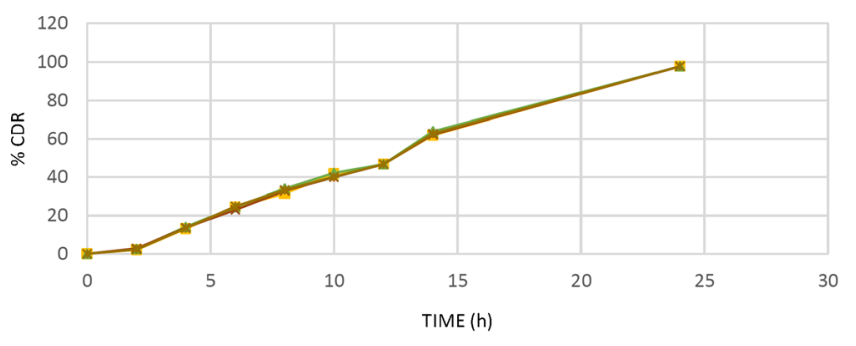

$\longrightarrow \mathrm{F3} \longrightarrow \mathrm{F9} \longrightarrow \mathrm{F} 10 \rightarrow \mathrm{F} 11 \rightarrow \mathrm{F} 14$

Fig. 2. a Drug release profile of F1, F2, F15, and F17 batches. b Drug release profile of F4, F5, F7, and F8 batches. c Drug release profile of F1, F6, F12, and F13 batches. d Drug release profile of F3, F9, F10, F11, and F14 batches

Drug Release as a Function of Agitation Intensity

To study the effect of agitation intensity on drug release, in vitro drug release studies were performed for optimized formulation at relatively high $(100 \mathrm{rpm})$, medium $(75 \mathrm{rpm})$, and low $(50 \mathrm{rpm})$ agitation intensity using USP-II (paddle) type dissolution apparatus. Results obtained were compared using difference factors and similarity factors.

Physical Observation of CPOP Before and After Drug Release Study

To confirm physical integrity of the coated semipermeable membrane, physical changes in dimensions of CPOP were observed carefully after drug release study. The diameter of the tablet was measured before and after the drug release study.

Table IV. Summary of $P$ values Generated by ANOVA of R1 and R2

\begin{tabular}{lcr}
\hline Response & $\begin{array}{l}\text { R1 } \\
P \text { value }\end{array}$ & \multicolumn{1}{l}{$\begin{array}{l}\text { R2 } \\
P \text { value }\end{array}$} \\
\hline Model & $<0.0001$ & $<0.0001$ \\
A & $<0.0001$ & $<0.0001$ \\
B & $<0.0001$ & $<0.0001$ \\
C & $<0.0001$ & 0.0002 \\
AB & 0.0719 & 0.0557 \\
AC & - & 0.4935 \\
BC & 0.0291 & 0.0759 \\
A $^{2}$ & - & 0.0005 \\
$B^{2}$ & $<0.0001$ & $<0.0001$ \\
$C^{2}$ & - & 0.0953 \\
\hline
\end{tabular}

\section{Surface Morphology Study of Coating Membrane}

The morphology of coating film was studied before and after drug release study of tablet by scanning electron microscopy (SEM-JSM 5610). The tablets were dried overnight at $40^{\circ} \mathrm{C}$ before SEM analysis. The samples were mounted on double coated conductive carbon tape. The scanning of samples was performed at $15 \mathrm{kv}$ with magnification ranging from 50 to $550 \times$ and spatial resolution ranging from of 20 to $100 \mu \mathrm{m}$.

\section{Accelerated Stability Study}

The stability study of optimized formulation was carried out at accelerated conditions $\left(40 \pm 2^{\circ} \mathrm{C}\right.$ and $75 \pm 5 \%$ $\mathrm{RH})$ for 3 months as per $\mathrm{ICH}$ guidelines. The formulation was analyzed for physical characteristics, assay, and release profile at the end of 3 months (21). Similarity factors and difference factors were evaluated for comparison of the drug release profile.

\section{In Vivo Pharmacokinetic Study}

In vivo experiments were approved by Institutional Animal Ethics Committee (IAEC) and performed as per the guidelines of Committee for the Purpose of Control and Supervision of Experiments on Animals (CPCSEA), Ministry of Environment and Forests, Government of India. New Zealand white rabbits (weighing 2.0-2.5 kg) were used in the experiment. The overnight-fasted rabbits $(n=3)$ were divided in two groups i.e., Tapentadol IR tablet (Group 1) and Tapentadol CPOP (Group 2). The mini tablets of $4 \mathrm{~mm}$ diameter were prepared according to the dose of the drug calculated based on the formula (22). Marketed Tapentadol IR 

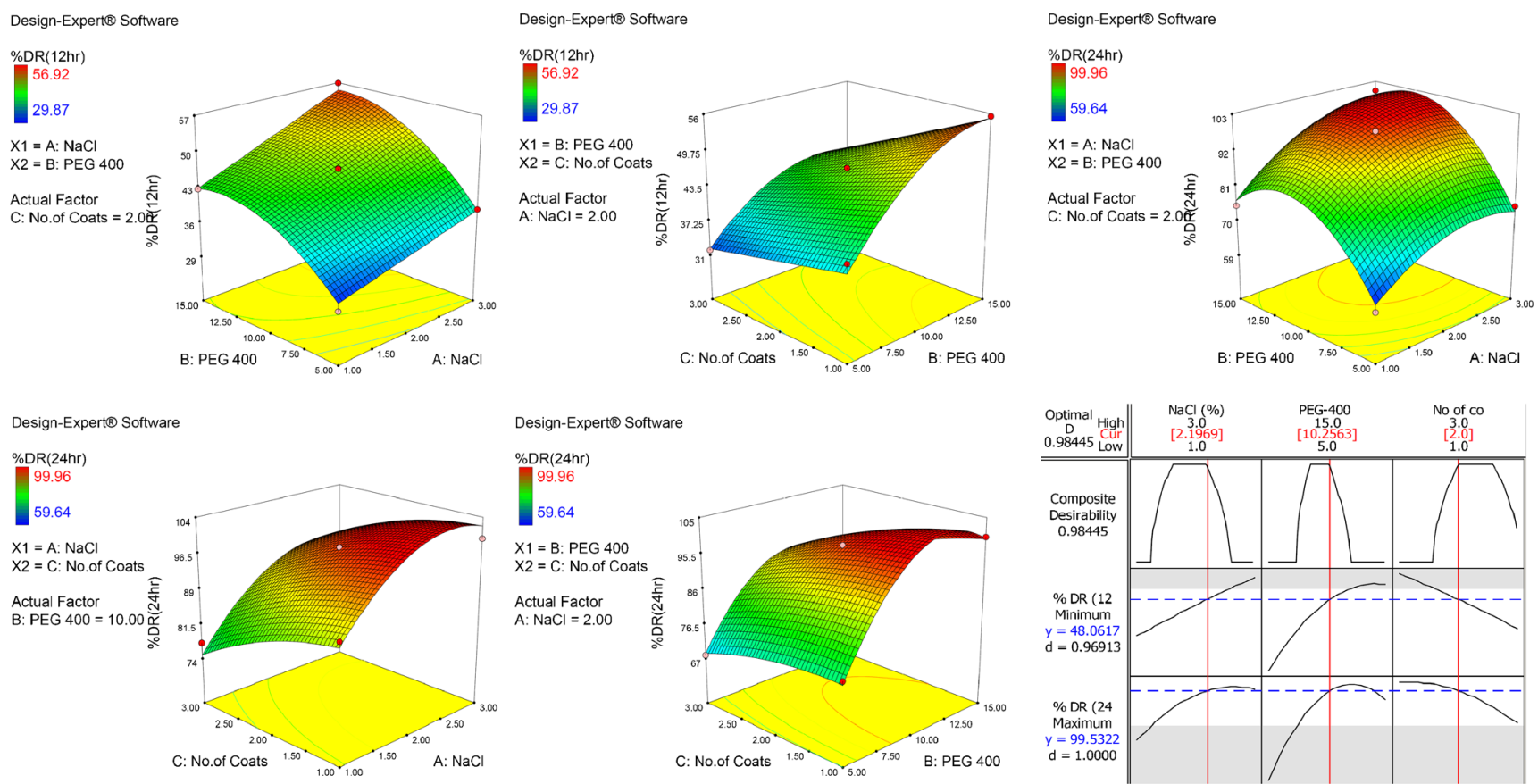

Fig. 3. Response surface graphs and desirability plot for \% CDR at 12 h (R1) and \% CDR at 24 h (R2)

tablet was crushed and recompressed to form $4 \mathrm{~mm}$ mini tablet containing same dose.

Human equivalent dose $=\frac{\text { Animal dose }(\mathrm{mg} / \mathrm{kg}) \times \text { Animal factor }}{\text { Human factor }}$

\section{High Performance Liquid Chromatography (HPLC)}

HPLC was performed on Shimadzu (Shimadzu Corporation, Kyoto, Japan) chromatographic system. The chromatographic separation was performed using a Kromasil C18 $(250 \mathrm{~mm} \times 4.6 \mathrm{~mm}$ i.d; $5 \mu$ particle size) column. Separation was achieved using a mobile phase consisting of a mixture of $20 \mathrm{mM}$ phosphate buffer $\mathrm{pH} 3.0$ and acetonitrile in the ratio of 45:55 $(v / v)$. The mobile phase was vacuum-filtered through a $0.22-\mu$ nylon membrane filter (Merck Millipore) followed by degassing in an ultrasonic bath and pumped at a flow rate of $0.8 \mathrm{ml} / \mathrm{min}$. The eluent was monitored using UV detector at a wavelength of $272 \mathrm{~nm}$. Data acquisition and integration was performed using LC Solution software (23).

\section{Plasma Sample Preparation Method}

Blood samples ( $0.5 \mathrm{ml}$ each) were collected from ear marginal vein at $1,2,4,6,8,10,12,24,36$, and $48 \mathrm{~h}$. with a 22-gauge needle in a microcentrifuge tube $(1.5 \mathrm{ml})$. The blood samples were

Table V. Suitability of Predicted Desirability Plot for Optimized Formulation

Response Predicted response Desirability Obtained response

\begin{tabular}{llll}
\hline R1 & 48.0617 & 0.969 & 49.02 \\
R2 & 99.5322 & 1.000 & 99.58 \\
\hline
\end{tabular}

immediately centrifuged (REMI Laboratory Instruments, Mumbai; CPR-30) at $3500 \mathrm{rpm}$ for $10 \mathrm{~min}$ at room temperature. The plasma samples obtained by centrifugation of blood were stored at $-70^{\circ} \mathrm{C}$ until analysis by HPLC method. Before analysis the samples were thawed at not more than $37^{\circ} \mathrm{C}$. The mixture of diethyl ether $\left(\mathrm{Et}_{2} \mathrm{O}\right)$ and dichloromethane $(\mathrm{DCM})$ in the ratio of $7: 3(v / v)$ was used as extraction solvent. The extraction solvent $(0.4 \mathrm{ml})$ was added to the centrifuge tube containing $0.25 \mathrm{ml}$ plasma. The tube was vortexmixed for $2 \mathrm{~min}$ and centrifuged at $13,000 \mathrm{rpm}$ for $10 \mathrm{~min}$ at $4^{\circ} \mathrm{C}$. $0.3 \mathrm{ml}$ of organic layer was transferred into microcentrifuge tube $(1.5 \mathrm{ml})$ for back-extraction using $0.2 \mathrm{ml}, 0.05 \mathrm{M} \mathrm{HCl}$ :Acetonitrile $(1: 1, v / v)$ for $10 \mathrm{~min}$. It was centrifuged at $13,000 \mathrm{rpm}$ for $10 \mathrm{~min}$ at $4^{\circ} \mathrm{C}$. The aqueous phase was collected and used for the HPLC analysis $(24,25)$.

The parameters such as peak plasma concentration attained by drug $\left(C_{\max }\right)$, mean residence time (MRT), time to attain peak concentration $\left(t_{\max }\right)$, elimination rate constant $\left(K_{\mathrm{e}}\right)$, biological half-life $\left(T_{1 / 2}\right)$ and area under the curve (AUC) were calculated (26).

\section{RESULTS}

\section{Drug-Excipients Compatibility Study}

The results of DSC study are shown in Fig. 1. The DSC thermogram shows sharp endothermic peak at $204.07^{\circ} \mathrm{C}$ corresponding to the melting point of TAP. The DSC thermogram of the CPOP also shows endothermic peak at the same temperature.

\section{Post Compression Characterization of Core Tablet}

Hardness of all the tablet batches was in the range of 5.02 to $5.98 \mathrm{~kg} / \mathrm{cm}^{2}$. Maximum friability recorded was $0.41 \%$. Thickness of the tablets was found varying from 3.2 to 


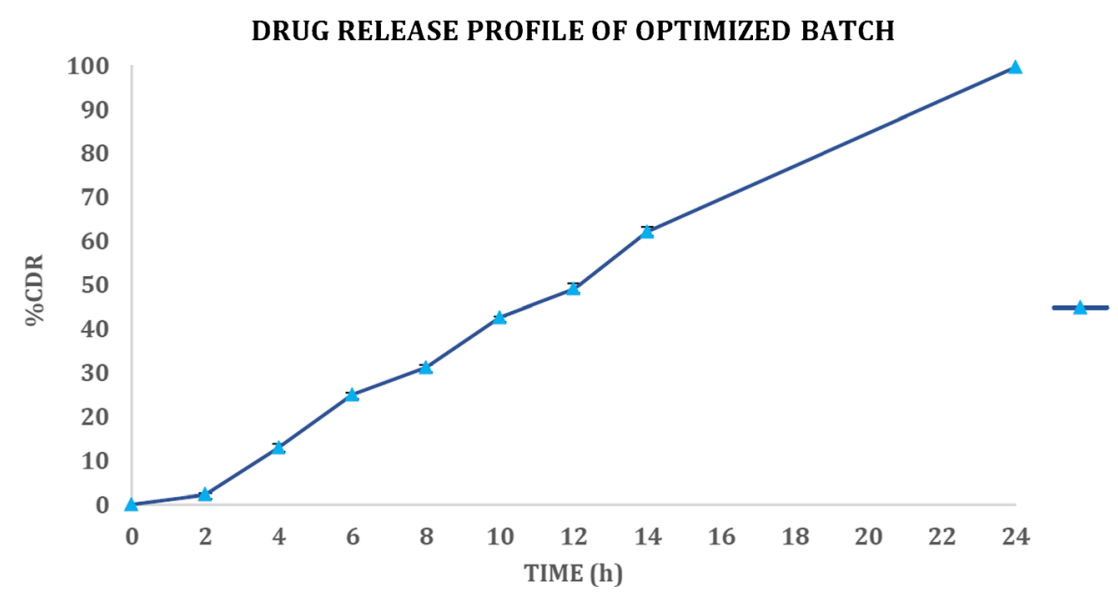

Fig. 4. Drug release profile of the optimized formulation

$3.4 \mathrm{~mm}$. Maximum and minimum average weight of all the tablet formulations were found to be 252.8 and $248.3 \mathrm{mg}$, respectively. None of the tablet showed weight variation more than $3 \%$ and was thus found within the desired range of $\pm 7.5 \%$. Drug content (\%) was found ranging from 98.84 to $100.47 \%$.

\section{In Vitro Drug Release Study}

The results of in vitro drug release study of all 17 batches are shown in Fig. 2. The results are grouped in a way to check the effect of osmogen concentration, pore former concentration, and number of coats on drug release. The results of \% CDR at 12 and at $24 \mathrm{~h}$ are given in Table I.

\section{Statistical Analysis}

Response Coefficient Significance Study

The results of two dependent variables i.e., \% CDR at $12 \mathrm{~h}$ and \% CDR at $24 \mathrm{~h}$ (Table I) were added to the statistical design generated by the Design expert software 7.0.0 and polynomial equations were generated to quantify the effect of the formulation variables on the responses variables. To determine significant factors (at 5\% level of significance)

Table VI. Composition of the Optimized Formulation

\begin{tabular}{ll}
\hline Ingredient & Quantity (mg) \\
\hline Tapentadol hydrochloride & 200 \\
$\mathrm{NaCl}$ & 5.47 \\
Microcrystalline cellulose & 34.45 \\
Polyvinyl pyrrolidone & 6.25 \\
Magnesium stearate & 3.0 \\
Aerosil & 0.83 \\
Total weight & 250 \\
Tablet coating composition & \\
Eudragit RSPO & $3.75 \mathrm{gm}$ \\
Eudragit RLPO & $1.25 \mathrm{gm}$ \\
PEG 400 & $0.51 \mathrm{gm}$ \\
\% weight gain & $10 \%$ \\
\hline
\end{tabular}

affecting the response variables, $P$ values generated from the software were used (Table IV).

$$
\begin{aligned}
\mathbf{R 1}(\% \mathbf{C D R} \text { at } 12 \mathbf{h})= & 46.53+4.95 \mathbf{A}+7.12 \mathbf{B}-4.48 \mathbf{C} \\
& +1.36 \mathbf{A B}-1.72 \mathbf{B C}-4.49 \mathbf{B}^{2} \\
\mathbf{R 2}(\% \mathbf{C D R} \text { at } 24 \mathbf{h})= & 97.83+8.11 \mathbf{A}+9.87 \mathbf{B}-5.66 \mathbf{C} \\
& +2.49 \mathbf{A B}+0.78 \mathbf{A C}-2.26 \mathbf{B C}-6.46 \mathbf{A}^{2} \\
& -14.12 \mathbf{B}^{2}-2.04 \mathbf{C}^{2}
\end{aligned}
$$

Interaction Study Between Independent Factors

The possible interaction between various combinations of the independent variables that can affect the response parameters were studied and are graphically represented as response surface plots (Fig. 3). To observe the interaction effects of two factors simultaneously, one of the three factors was kept constant.

\section{Optimization Using Desirability Plot}

A composite desirability of 0.984 was obtained from the software (Fig. 3). Values for R1 and R2 predicted from software were 48.06 and 99.53, respectively. The desirability values for R1 and R2 were 0.969 and 1.00, respectively (Table V). The drug release profile of the optimized formulation is shown in Fig. 4. The experimental values for R1 and R2 obtained were 49.02 and 99.58 , respectively, being in good agreement with the predicted value.

\section{Validation of Polynomial Equations Generated by Model}

The polynomial equation generated by experimental design was validated by preparing extra check point batches $\mathrm{C} 1$ and C2 (Table III). The actual values obtained were compared with the predicted values from the design expert software.

\section{Selection of Optimized Formulation}

The optimized values obtained by using Minitab 16 software with good desirability values were confirmed with actual values of the responses. The composition of optimized batch was determined, in which concentration of $\mathrm{NaCl}$ was $2.19 \%$ and concentration of PEG 400 was $10.25 \%$ keeping target value for coating at two numbers of coats (Table VI). 
Table VII. Summary of the Mathematical Modeling of Release Profile of an Optimized Batch

\begin{tabular}{|c|c|c|c|c|c|c|c|c|c|}
\hline \multicolumn{2}{|c|}{ Zero-order } & \multicolumn{2}{|c|}{ First-order } & \multicolumn{2}{|c|}{ Higuchi } & \multicolumn{2}{|c|}{ Hixson-Crowell } & \multicolumn{2}{|c|}{ Korsmeyer-Peppas } \\
\hline$r^{2}$ & $K_{0}$ & $r^{2}$ & $K_{1}$ & $r^{2}$ & $K_{\mathrm{H}}$ & $r^{2}$ & $K_{\mathrm{HC}}$ & $r^{2}$ & $n$ \\
\hline 0.993 & 4.376 & 0.832 & -0.08 & 0.976 & 27.70 & 0.925 & -0.15 & 0.941 & 1.467 \\
\hline
\end{tabular}

\section{Mathematical Modeling of Drug Release Profile}

Drug release data of the optimized formulation were fitted to various mathematical models (Zero-order, First-order, Higuchi, Korsmeyer-Peppas, and Hixson-Crowell) to check the kinetics of drug release. The best goodness-of-fit test $\left(r^{2}\right)$ were taken as criteria for selecting the most appropriate model (Table VII). The value of $r^{2}$ for zero-order release model was found to be 0.993 ; which was highest amongst all the kinetic models applied.

\section{Investigation of Drug Release Mechanism}

In order to confirm that osmotic pressure difference is the driving force for drug release from the developed CPOP, in vitro drug release study was carried out in $0.1 \mathrm{~N} \mathrm{HCl}, 1 \mathrm{~mol} / \mathrm{lit}$ $\mathrm{NaCl}$ and $2 \mathrm{~mol} / \mathrm{lit} \mathrm{NaCl}$ as dissolution medium (all the dissolution media at $\mathrm{pH}$ 1.2) (Fig. 5) showing a \% CDR of 99.59, 81.18 , and $70.98 \%$ respectively.

\section{Effect of pH}

The in vitro release study of optimized batch was carried out in different dissolution media having $\mathrm{pH} 1.2,4.5$ and 6.8 (Fig. 6). The similarity factor and difference factor had been calculated. Values for similarity factor between $\mathrm{pH} 1.2$ and 4.5, $\mathrm{pH} 4.5$ and 6.8 , and $\mathrm{pH} 1.2$ and 6.8 were found to be 68.94, 64.37 , and 74.15, respectively. Values for difference factor (f1) between $\mathrm{pH} 1.2$ and 4.5, $\mathrm{pH} 4.5$ and 6.8, and $\mathrm{pH} 1.2$ and 6.8 were found to be $11.48,14.38$, and 4.80 , respectively.

\section{Influence of Agitation Intensity on In Vitro Release Profile}

In vitro release of TAP was observed at three different rotational speeds i.e., 50, 75, and $100 \mathrm{rpm}$ (Fig. 7). Nonsignificant difference of release profile at varying rotational speed was confirmed by $\mathrm{f} 2$ values, which were found to be
75.95 (between 50 and $75 \mathrm{rpm}$ ), 59.98 (between 50 and $100 \mathrm{rpm}$ ) and 83.19 (between 100 and $75 \mathrm{rpm}$ ).

\section{Physical Observation and Surface Morphology}

Physical change in the dimension of the tablet was observed after drug release study. Diameter of the tablet before and after drug release study was 9 and $12 \mathrm{~mm}$ respectively (Fig. 8). The shape of the tablet changed to oval, which was filled with liquid inside. The semipermeable membrane was found intact after completion of drug release study. The morphological changes in semipermeable membrane are shown by SEM images (Fig. 9).

\section{Accelerated Stability Study}

Stability study of optimized formulation was carried out at accelerated conditions for 3 months (Table VIII). The samples were stored at $40 \pm 2{ }^{\circ} \mathrm{C}$ with $75 \pm 5 \%$ relative humidity and the drug release study was performed using $900 \mathrm{ml}$ of $0.1 \mathrm{~N}$ Hydrochloric acid $(\mathrm{HCl})$ as dissolution medium for initial $2 \mathrm{~h}$ followed by phosphate buffer $\mathrm{pH} 6.8$ for remaining $22 \mathrm{~h}$. The stirring rate was $50 \mathrm{rpm}$ and dissolution media was maintained at $37 \pm 1^{\circ} \mathrm{C}$. The comparative evaluation of results of drug release study was performed (Fig. 10). There was no change in physical appearance and weight variation. The results of the assay obtained initially and after 3 months were 99.12 and $98.63 \%$, respectively. Percent CDR at 12 and $24 \mathrm{~h}$ after 3 months were 54.12 and $97.57 \%$, respectively.

\section{In Vivo Study}

The results of plasma concentration vs time profile for Tapentadol IR tablet and Tapentadol CPOP formulation are shown in Fig. 11. The values of $T_{\max }$, MRT, AUC and $T_{1 / 2}$ were found $8 \mathrm{~h}, 18.09 \mathrm{~h}, 2568.82 \mathrm{~h} \times \mathrm{ng} / \mathrm{ml}$, and $9 \mathrm{~h}$, respectively for CPOP formulation; which were higher than the marketed

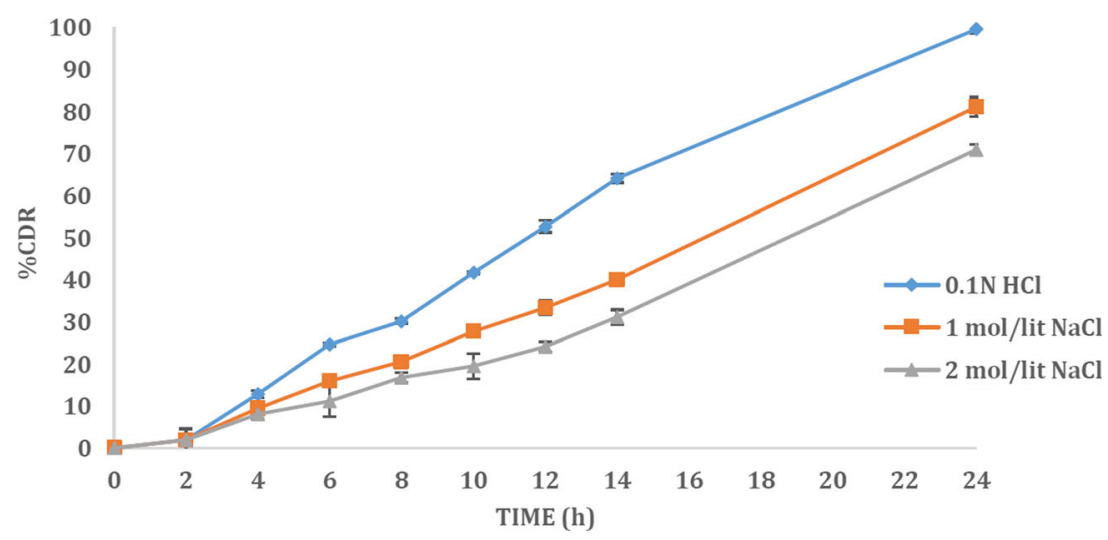

Fig. 5. Drug release profile at three dissolution mediums having different osmolarities 


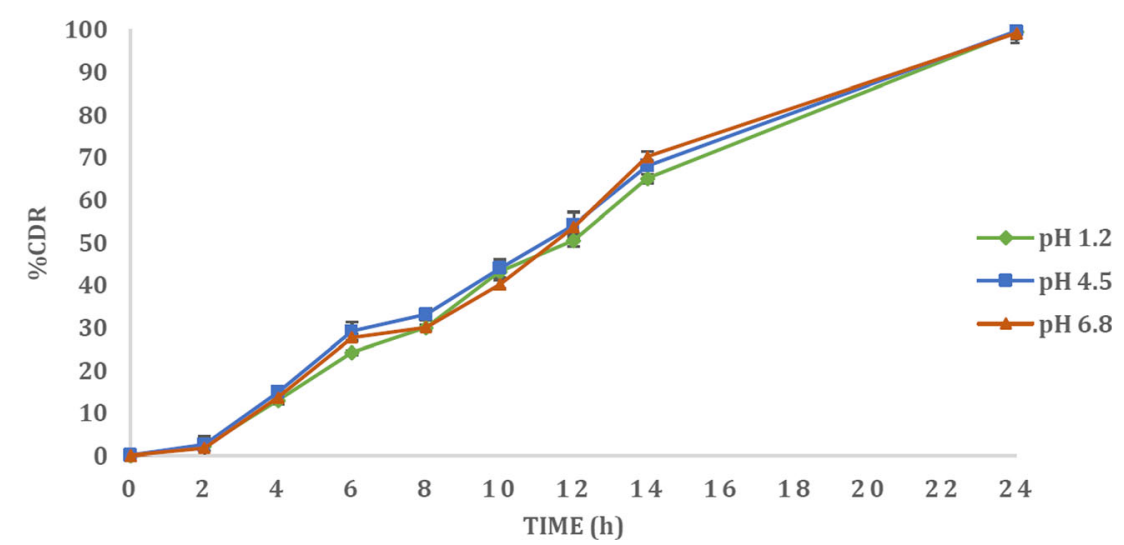

Fig. 6. Drug release profile of optimized formulation under three different $\mathrm{pH}$ conditions

tablet. The values for $K_{\mathrm{e}}$ and $C_{\max }$ were found $0.07 \mathrm{~h}^{-1}$ and $188.66 \mathrm{ng} / \mathrm{ml}$ for the prepared CPOP formulation; which were lower than the marketed tablet (Table IX).

\section{DISCUSSION}

Controlled porosity osmotic pump (CPOP) is one of the types of oral osmotic drug delivery systems, used to deliver the drug at zero-order for prolonged period of time which decreases the frequency of administration and hence, improves patient compliance. As TAP has a relatively short biological half-life $(\sim 4 \mathrm{~h})$, it is to be administered 3-4 times a day so there was a strong need to develop a once a day formulation. Moreover, TAP has a low molecular weight $(<500 \mathrm{Da})$ and belongs to BCS class-I, which makes TAP a suitable candidate for the development of CPOP (6).

Components for the development of CPOP were initially screened on the basis of literature review and some preliminary trials. $\mathrm{NaCl}$ was selected as an osmogen in core part to develop optimum osmotic pressure within. Many other agents like mannitol, sucrose, fructose, potassium sulfate etc. can be used as osmogens. However, amongst all these agents, $\mathrm{NaCl}$ generates high osmotic pressure at a relatively low amount $(27,28)$ resulting in an acceptable tablet weight and hence, was selected for the present study. Eudragit RSPO and Eudragit RLPO were chosen to form a semipermeable membrane around the core. Eudragit RSPO possesses very less water permeability while Eudragit RLPO has high permeability to water (29). The different combinations of both the polymers can be used to form semipermeable membrane with desired water permeability. Various channeling agents tried during preliminary batches were PEG 6000, dibutyl phthalate (DBP), diethyl phthalate (DEP), dibutyl sebacate (DBS), and PEG 400 (30,31). It was found that the lag time observed with tablets coated by incorporating dibutyl sebacate as channeling agent was reduced when a hydrophilic pore former like PEG 400 was incorporated in semipermeable membrane. A high lag time was also observed in the case of PEG 6000, which might be due to its higher molecular weight and lower dissolution rate. Thus, PEG 400 was selected as water-soluble pore forming agent. All other excipients chosen were based on practical experience and literature review $(32,33)$. The compatibility of TAP and other selected excipients was confirmed from the results of DSC study. There was no change in the position of the peak in DSC thermograms of the CPOP and the drug.

The flow properties of final mixture of drug and excipient were evaluated by measuring the parameters such as angle of repose, Carr's index and Hausner's ratio. The values obtained indicated good flow characteristics, which lead to uniform die filling during direct compression of tablets, ultimately resulting in uniform tablet weight (11).

Hardness of the tablet was intentionally kept at a relatively higher range to reduce the friability of the tablets. It was

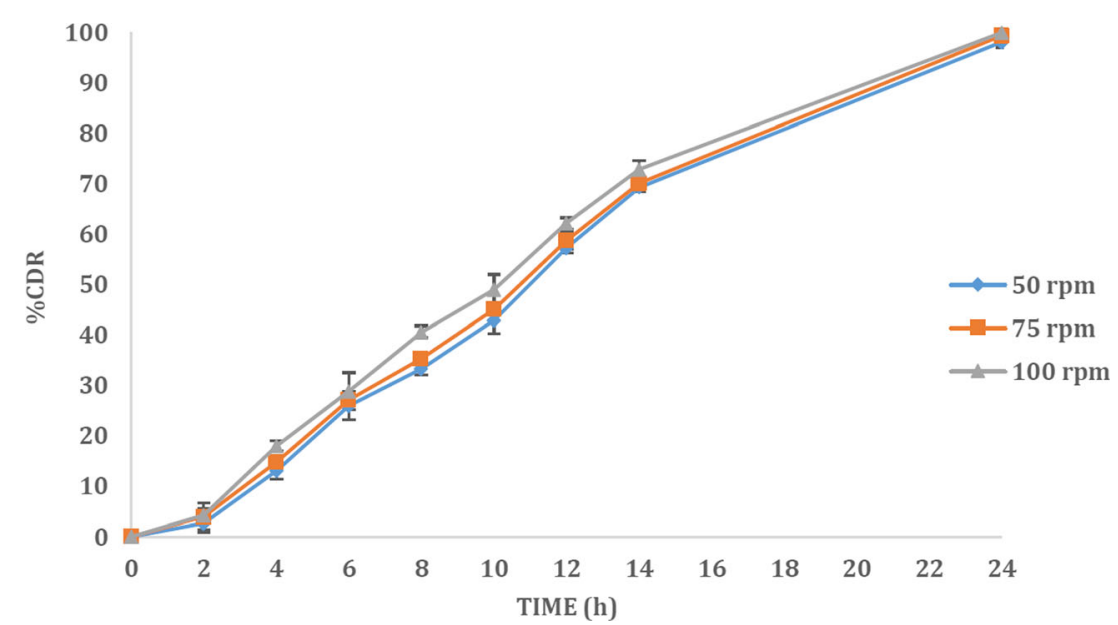

Fig. 7. Drug release profile of optimized formulation under three different agitation speeds 


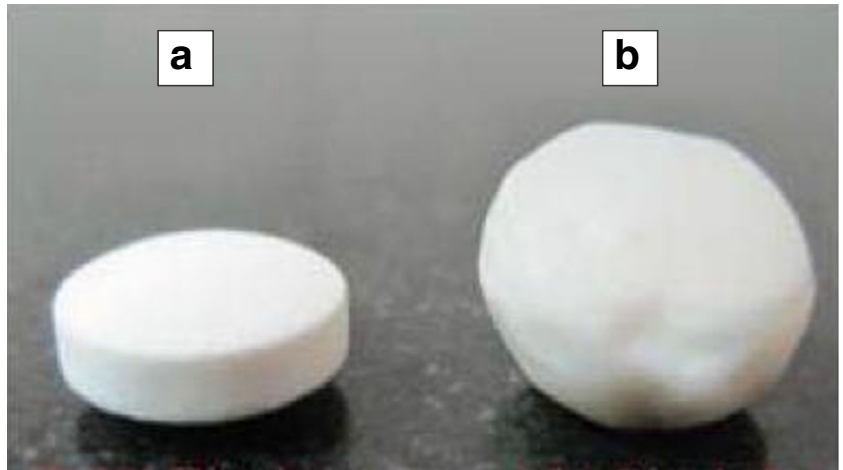

Fig. 8. Size of CPOP (a) before drug release, and (b) after drug release

necessary to keep the friability at the lowest possible level as impact and attrition forces exerted during the coating process may lead to an improper coating and formation of an uneven semipermeable membrane. Uniform die filling resulted in uniform thickness of the tablet.

In vitro drug release study was performed at $37 \pm 1^{\circ} \mathrm{C}$ temperatures and at two different dissolution media to mimic physiological environment. Initial drug release for $2 \mathrm{~h}$ was performed in $0.1 \mathrm{~N} \mathrm{HCl}$ and then, the remaining drug release was performed in phosphate buffer $\mathrm{pH}$ 6.8. Drug release profiles of all the batches are represented in Fig. 2 and grouped in such a way to better interpret the effect of all three factors on drug release from the formulation. Formulation batches F2, F4, F7, and F12 having $\mathrm{NaCl}$ concentration at low $(-1)$ level. Formulation batches F5, F6, F8, and F13 having $\mathrm{NaCl}$ concentration at Medium (0) level. Formulation batches $\mathrm{F} 1, \mathrm{~F} 15, \mathrm{~F} 16$, and $\mathrm{F} 17$ having $\mathrm{NaCl}$ concentration at High (+1) level. The remaining formulation batches F3, F9, F10, F11, and F14 were center point batches of the design with same composition of core tablet as well as coating membrane. It was observed from the comparison of drug release profile of F4 and F7 that the number of coats negatively affects the overall drug release from the formulation. The same effect was also observed by comparing the drug release profiles of F6 with F8 and F15 with F16. The effect of pore former could be observed by comparison of drug release profiles of $\mathrm{F} 2$ with F12; F5 with F8; and F1 with F17. As the concentration of pore former increases in coating membrane, the overall drug release increases with reduced lag time. The pore former having a high solubility in water readily forms pores in semipermeable membrane, which ultimately reduces the time of drug to come out from the system. Thus, the concentration of pore formers was found to affect drug release positively (34). By the comparison of drug release profile of F2, F4, F7 and F12; with F17, F16, F15 and F1, respectively, the effect of concentration of $\mathrm{NaCl}$ was found to be positively influencing the drug release. As the concentration of the $\mathrm{NaCl}$ affects the drug release after the pores are formed by PEG 400, the lag time remains unaffected by the concentration of $\mathrm{NaCl}$.

The design generated polynomial equations comprise the coefficients for intercept, first order main effects, interaction terms and higher order effects. Positive sign against the individual term indicates synergistic effect while negative sign indicates inverse effect of the factors. The value of the individual term represents relative intensity of that particular factor on response variables. The values of the coefficients $A, B$, and $C$ relate to the main effects of these variables on the corresponding response. It is evident from the polynomial equation of $\mathrm{R} 1$ that factor $A(\mathrm{NaCl})$ and factor $B$ (PEG 400), and their interactive term $A B$ affects positively while factor $C$ (number of coats) and interactive term $B C$ affects negatively to response $\mathrm{R} 1$. In the case of response $\mathrm{R} 2$, factors $A, B$, their interactive terms $A B$ and $A C$ contributes positively while factor $C$ and interactive term $A C$ contributes negatively.

A response surface graph (Fig. 3) shows the response as a function of factor level. Three dimensional response surface graphs for R1 and R2 were plotted for two factors only, keeping the third factor constant. Response surface graphs show significant influences of each independent variable on dependent variables. At higher levels of $\mathrm{NaCl}$, osmogen favors drug release due to increase in osmotic pressure. Again, PEG 400, which is responsible for generation of pores, affects the permeability of the outer coating film and its higher level leads to increased drug release. The character of variable $C$ was found to be opposite that of variable $A$ and $B$ for overall contribution to R1 and R2. With increased amount of tablet coating polymer, the coating thickness increases that leads to high barrier property of tablet surface towards water intake which consequently decreases drug release (35).

The optimization of formulation was done using desirability values, which predicts that if the formulation was prepared according to the obtained values of variables, the chances to obtain desired value of response would be $98.44 \%$. The obtained actual values were found in good agreement with the predicted values and thus the values were used to optimize formula for CPOP. The residual values obtained in

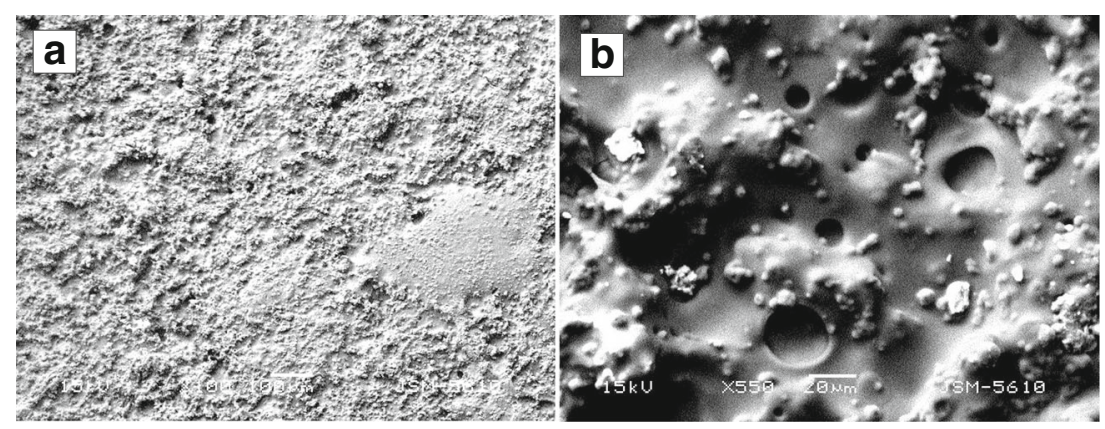

Fig. 9. SEM images of surface analysis of coating membrane (a) before and (b) after drug release study 
Table VIII. Stability Data of Optimized Batch Stored at Accelerated Conditions

\begin{tabular}{llclll}
\hline Sampling time & \multicolumn{3}{l}{ Evaluation parameters } & & \\
\cline { 2 - 6 } & Physical appearance & Weight variation (mg) & Assay (\%) & \% CDR (12 h) & \% CDR (24 h) \\
\hline Initial & White colored & $249 \pm 2.09$ & $99.12 \pm 1.69$ & $49.73 \pm 1.81$ & $99.89 \pm 0.59$ \\
After 3 months & White colored & $249 \pm 1.89$ & $98.63 \pm 1.49$ & $54.12 \pm 1.26$ & $97.57 \pm 0.52$ \\
\hline
\end{tabular}

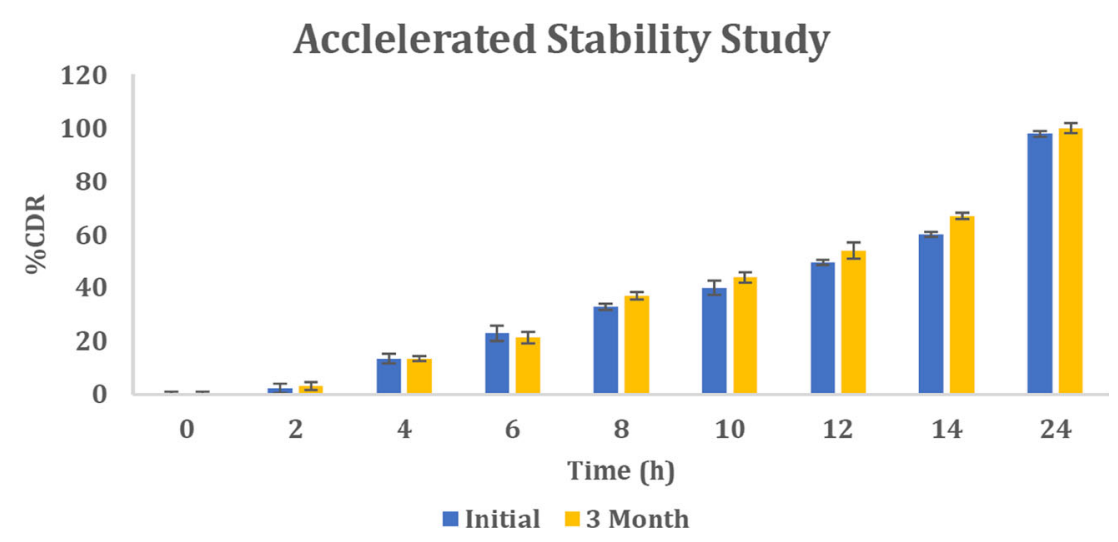

Fig. 10. Comparison of drug release pattern from CPOP initially and after storage at accelerated conditions for 3 months

checkpoint batches shows that the obtained actual values were very close to the predicted values, which confirm the validity of the generated statistical model. The drug release pattern was subjected to kinetic models fitting to confirm the release mechanism. Amongst all mathematical models, the best goodness of fit $\left(r^{2}\right)$ value for zero-order was found to be very close to 1 . Thus it was confirmed that the release of TAP from the developed CPOP follows zero-order. It was confirmed from the results shown in Fig. 5 that the osmotic pressure generated inside the tablet core by osmogen was the driving force for the drug release from the optimized CPOP. As the concentration of $\mathrm{NaCl}$ was increased in dissolution media, the difference between osmotic pressure generated at either side of the semipermeable membrane was reduced, which ultimately results in decrease in drug release rate from the CPOP system (36). The release of TAP was independent of $\mathrm{pH}$ and agitation intensities, which was confirmed by drug release profiles of the optimized formulation at varying $\mathrm{pH}$ and agitation/rotation speeds as shown in Figs. 6 and 7, respectively. The values of difference factor and similarity factor indicate that there was no significant difference between drug release profiles at different $\mathrm{pH}$ conditions as well as at different agitation intensities. In CPOP systems, $\mathrm{pH}$ and agitation intensity do not have any role in release mechanism of drugs (37). The physical observation of CPOP after completion of drug release study showed that increase in size of the tablet due to osmotic pressure leads to inflow of dissolution medium though the semipermeable membrane. The intact semipermeable membrane

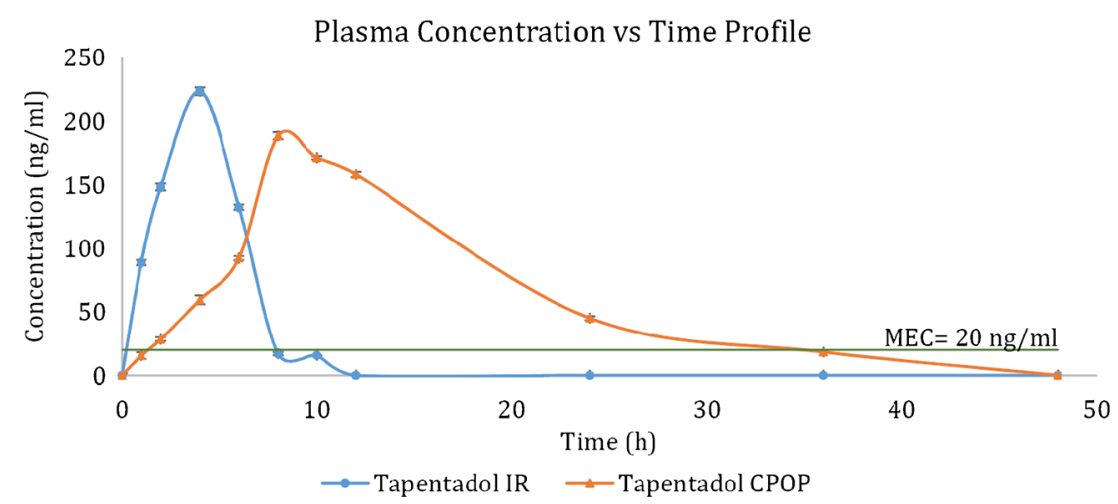

Fig. 11. Comparison of plasma concentration $v s$ time profile for Tapentadol HCl IR tablet and $\mathrm{CPOP}$ formulation 
Table IX. Pharmacokinetic Parameters After In Vivo Study

\begin{tabular}{|c|c|c|}
\hline Parameters & Tapentadol IR tablet & CPOP formulation \\
\hline$C_{\max }(\mathrm{ng} / \mathrm{ml})$ & $223.38 \pm 20.13$ & $188.66 \pm 39.57$ \\
\hline$T_{\max }(\mathrm{h})$ & $4.0 \pm 0.5$ & $8.0 \pm 0.5$ \\
\hline$T_{1 / 2}(\mathrm{~h})$ & $2.0 \pm 0.8$ & $9.0 \pm 0.7$ \\
\hline $\mathrm{AUC}_{0-t}(\mathrm{~h} \times \mathrm{ng} / \mathrm{ml})$ & $1091.15 \pm 103.12$ & $2568.82 \pm 198.43$ \\
\hline MRT (h) & $4.56 \pm 0.9$ & $18.09 \pm 0.8$ \\
\hline$K_{\mathrm{e}}\left(\mathrm{h}^{-1}\right)$ & $0.35 \pm 0.04$ & $0.07 \pm 0.02$ \\
\hline
\end{tabular}

after drug release study confirmed integrity of the CPOP system, which eliminates the chances of burst release of the drug due to system failure. SEM images of the semipermeable membrane confirms no pores before drug release study and clearly generated pores due to leaching of PEG 400 into aqueous media after completion of drug release study for $24 \mathrm{~h}$.

After oral administration, TAP was detectable In plasma within $1 \mathrm{~h}$. The absorption was rapid for IR tablet as indicated by a low $T_{\max }$ value $(4 \mathrm{~h})$; whereas the CPOP formulation exhibited delayed absorption as indicated by a relatively high $T_{\max }$ value $(8 \mathrm{~h})$. The $C_{\max }$ value for IR tablet was high as compared to CPOP formulation. The rapid elimination of the TAP in case of IR tablet was further supported by high value of elimination rate constant $\left(\mathrm{K}_{\mathrm{e}}=0.35\right)$. On the other hand; for CPOP formulation, value of half-life was high and elimination rate constant was low, indicating that drug remains in the body for longer period of time. This was further supported by high value of MRT in comparison with IR tablet. The low value of AUC observed for IR tablet may be due to its rapid absorption and elimination from the body. However, the CPOP formulation showed higher AUC values showing a 2.35-fold increase in relative bioavailability of TAP. In the case of prepared CPOP, the drug concentration in plasma was above the minimum effective concentration (MEC) of $20 \mathrm{ng} / \mathrm{ml}$ up to $24 \mathrm{~h} \mathrm{(6).} \mathrm{The} \mathrm{results} \mathrm{of} \mathrm{phar-}$ macokinetic studies shows that an increase in MRT, leads to reduction in dosing frequency and side effects resulting in increased patient compliance. The results of stability studies suggest that the developed formulation was stable for 3 months at accelerated conditions.

\section{CONCLUSION}

The results revealed that the prepared CPOP is able to deliver more than $95 \%$ of TAP at zero-order kinetics up to $24 \mathrm{~h}$. The release of the drug from developed CPOP was found to be independent of physiological conditions of gastric lumen. The in vivo studies showed a significant increase in the MRT and AUC compared to the marketed tablet indicating a successful development of once a day formulation of TAP with enhanced bioavailability. The stability studies showed that the formulation remained stable for 3 months at accelerated conditions.

\section{COMPLIANCE WITH ETHICAL STANDARDS}

In vivo experiments were approved by Institutional Animal Ethics Committee (IAEC) and performed as per the guidelines of Committee for the Purpose of Control and Supervision of Experiments on Animals (CPCSEA), Ministry of Environment and Forests, Government of India.

Conflicts of Interest The authors declare that they have no competing interests.

\section{REFERENCES}

1. Tschentke TM, de Vry J, Terlinden R, Hennies H-H, Lange C, Strassburger W, et al. Tapentadol hydrochloride. Drugs Future. 2006;31(12):1035-134.

2. Kalso E, Edwards JE, Moore RA, McQuay HJ. Opioids in chronic non-cancer pain: systematic review of efficacy and safety. Pain. 2004;112(3):372-80.

3. Porreca F, Ossipov MH. Nausea and vomiting side effects with opioid analgesics during treatment of chronic pain: mechanisms, implications, and management options. Pain Med. 2009;10(4):654-62.

4. Sánchez del Águila MJ, Schenk M, Kern K-U, Drost T, Steigerwald I. Practical considerations for the use of Tapentadol prolonged release for the management of severe chronic pain. Clin Ther. 2015;37(1):94-113.

5. Janssen Pharmaceuticals Inc. NUCYNTA®ER- Tapentadol hydrochloride tablet, film coated, extended release: U.S. NATIONAL LIBRARY OF MEDICINE. 2014. http:// dailymed.nlm.nih.gov/dailymed/drugInfo.cfm?setid=f4c911f3484b-44fa-833e-2d970d39be8f. Accessed 24 July 2015.

6. Terlinden R, Ossig J, Fliegert F, Lange C, Gohler K. Absorption, metabolism, and excretion of 14C-labeled Tapentadol $\mathrm{HCl}$ in healthy male subjects. Eur J Drug Metab Pharmacokinet. 2007;32(3):163-9.

7. Verma RK, Krishna DM, Garg S. Formulation aspects in the development of osmotically controlled oral drug delivery systems. J Control Release Off J Control Release Soc. 2002;79(13):7-27.

8. Gupta BP, Thakur N, Jain NP, Banweer J, Jain S. Osmotically controlled drug delivery system with associated drugs. J Pharm Pharm Sci Publ Can Soc Pharm Sci Soc Can Sci Pharm. 2010;13(4):571-88.

9. Marini A, Berbenni V, Pegoretti M, Bruni G, Cofrancesco P, Sinistri C, et al. Drug-excipient compatibility studies by physicochemical techniques; the case of atenolol. J Therm Anal Calorim. 2003;73(2):547-61.

10. Serajuddin AT, Thakur AB, Ghoshal RN, Fakes MG, Ranadive SA, Morris KR, et al. Selection of solid dosage form composition through drug-excipient compatibility testing. J Pharm Sci. 1999;88(7):696-704.

11. Shah RB, Tawakkul MA, Khan MA. Comparative evaluation of flow for pharmaceutical powders and granules. AAPS PharmSciTech. 2008;9(1):250-8.

12. Ferreira SLC, Bruns RE, da Silva EGP, dos Santos WNL, Quintella CM, David JM, et al. Statistical designs and response surface techniques for the optimization of chromatographic systems. J Chromatogr A. 2007;1158(1-2):2-14.

13. Das SK, Yuvaraja K, Khanam J, Nanda A. Formulation development and statistical optimization of ibuprofen-loaded polymethacrylate microspheres using response surface methodology. Chem Eng Res Des. 2015;96:1-14.

14. Baş D, Boyacı İH. Modeling and optimization I: usability of response surface methodology. J Food Eng. 2007;78(3):83645.

15. Maleki Dizaj S, Lotfipour F, Barzegar-Jalali M, Zarrintan M-H, Adibkia K. Box-Behnken experimental design for preparation and optimization of ciprofloxacin hydrochloride-loaded $\mathrm{CaCO} 3$ nanoparticles. J Drug Delivery Sci Technol. 2015;29:125-31.

16. Mishra M, Mishra B. Design and evaluation of microporous membrane coated matrix tablets for a highly water soluble drug. Chem Pharm Bull. 2010;58(7):995-1000. 
17. Shah B, Raichandani Y, Misra A. Development and evaluation of oral osmotic pump of butorphanol tartrate. Pharm Dev Technol. 2014;19(7):868-80.

18. Dash S, Murthy PN, Nath L, Chowdhury P. Kinetic modeling on drug release from controlled drug delivery systems. Acta Pol Pharm. 2010;67(3):217-23.

19. Anderson NH, Bauer M, Boussac N, Khan-Malek R, Munden P, Sardaro M. An evaluation of fit factors and dissolution efficiency for the comparison of in vitro dissolution profiles. J Pharm Biomed Anal. 1998;17(4-5):811-22.

20. Xie F, Ji S, Cheng Z. In vitro dissolution similarity factor (f2) and in vivo bioequivalence criteria, how and when do they match? Using a BCS class II drug as a simulation example. Eur J Pharm Sci. 2015;66:163-72.

21. Stability testing of new drug substances and products Q1A(R2). 2003.

22. Reagan-Shaw S, Nihal M, Ahmad N. Dose translation from animal to human studies revisited. FASEB J Off Publ Fed Am Soc Exp Biol. 2008;22(3):659-61.

23. Bhatasana PT, Parmar AR. Development and validation of RPHPLC method for estimation of Tapentadol hydrochloride in its tablet dosage form. Der Pharmacia Sin. 2012;3(4):422-6.

24. Giorgi M, Meizler A, Mills PC. Quantification of Tapentadol in canine plasma by HPLC with spectrofluorimetric detection: development and validation of a new methodology. J Pharm Biomed Anal. 2012;67-68:148-53.

25. Lee HK, Lebkowska-Wieruszewska B, Kim TW, Kowaski CJ, Giorgi M. Pharmacokinetics of the novel atypical opioid Tapentadol after intravenous, intramuscular and subcutaneous administration in cats. Vet J. 2013;198(3):620-4.

26. Gao J, Liu C. Pharmacokinetics of 22 new molecular entity drugs approved in 2008. Asian J Pharmacodyn Pharmacokinet. 2009;9(2):89-116.

27. McClelland GA, Sutton SC, Engle K, Zentner GM. The solubility-modulated osmotic pump: in vitro/in vivo release of diltiazem hydrochloride. Pharm Res. 1991;8(1):88-92.
28. Ali AA, Sayed OM. Development and characterization of ketorolac tromethamine osmotic pump tablets. J Drug Deliv Sci Technol. 2013;23(3):275-81.

29. Rowe RC, Sheskey PJ, Quinn ME, Association AP. Handbook of pharmaceutical excipients. 6th ed. Pharmaceutical Press; 2009.

30. Verma RK, Kaushal AM, Garg S. Development and evaluation of extended release formulations of isosorbide mononitrate based on osmotic technology. Int J Pharm. 2003;263(1-2):9-24.

31. Xu W-J, Li N, Gao C-k. Preparation of controlled porosity osmotic pump tablets for salvianolic acid and optimization of the formulation using an artificial neural network method. Acta Pharm Sin B. 2011;1(1):64-70.

32. Malaterre V, Ogorka J, Loggia N, Gurny R. Oral osmotically driven systems: 30 years of development and clinical use. Eur J Pharm Biopharm. 2009;73(3):311-23.

33. Habib BA, Rehim RTAE, Nour SA. Feasibility of optimizing trimetazidine dihydrochloride release from controlled porosity osmotic pump tablets of directly compressed cores. J Adv Res. 2014;5(3):347-56.

34. Thombre AG, Zentner GM, Himmelstein KJ. Mechanism of water transport in controlled porosity osmotic devices. J Membr Sci. 1989;40(3):279-310.

35. Liu H, Yang X-G, Nie S-F, Wei L-L, Zhou L-L, Liu H, et al. Chitosan-based controlled porosity osmotic pump for colon-specific delivery system: screening of formulation variables and in vitro investigation. Int J Pharm. 2007;332(12):115-24.

36. Kumaravelrajan R, Narayanan N, Suba V. Development and evaluation of controlled porosity osmotic pump for nifedipine and metoprolol combination. Lipids Health Dis. 2011;10:51.

37. Abd-Elbary A, Tadros MI, Alaa-Eldin AA. Development and in vitro/in vivo evaluation of etodolac controlled porosity osmotic pump tablets. AAPS PharmSciTech. 2011;12(2):485-95. 